\title{
Eficiencia de celdas generadoras de gases oxidantes alimentadas con energía eléctrica o solar
}

\author{
Héctor Brust Carmona, ${ }^{1}$ Alfredo Benitez, ${ }^{1}$ Joaquín Zarco, ${ }^{1}$ \\ Enrique Sánchez ${ }^{1}$ e Ingrid Mascher ${ }^{1}$
}

RESUMEN Las enfermedades causadas por microorganismos contaminantes del agua siguen siendo un grave problema en países como México. La cloración mediante gas cloro o compuestos de cloro es uno de los mejores métodos para tratar el agua destinada al consumo humano. Sin embargo, la dificultad en el manejo del gas cloro y la ineficiencia de los sistemas de dosificación de soluciones de hipoclorito, debida a factores sociopoliticos, económicos y culturales, a veces han restado utilidad a estos procedimientos de cloración, sobre todo en comunidades rurales alejadas $y$ de difícil acceso. Por todo ello se han desarrollado tecnologías apropiadas para la desinfección del agua mediante la generación in situ de gases oxidantes (cloro y ozono) a partir de la electrólisis de una solución de sal común, el llamado sistema MOGGOD. La evaluación simulada del sistema mediante un modelo hidráulico permitió calcular sus costos parciales y totales. Con alimentación del sistema mediante energía eléctrica de la red se obtuvo una eficiencia de 90\% y se generaron en 10 horas gases suficientes para desinfectar cerca de $200 \mathrm{~m}^{3}$ de agua a un costo aproximado de N\$ 8 (US\$1,30). La celda electrolítica funciona también con energía eléctrica suministrada mediante célula fotoeléctrica, en cuyo caso los costos de inversión son mayores. El sistema alimentado con células fotovoltaicas puede estar justificado en comunidades aisladas que carecen de energía eléctrica pero que cuentan con un sistema de distribución de agua por gravedad.

Tanto en México como en la mayoría de los países latinoamericanos, uno de los problemas de salud pública más importantes son las infecciones y parasitosis intestinales y cutáneas, relacionadas entre otros factores con el uso y consumo de agua sin desinfección, purificación o potabilización $(1,2)$. La

\footnotetext{
1 Centro de Desarrollo y Aplicaciones Tecnológicas (CEDAT), Secretaría de Salud, México, DF. La correspondencia debe dirigirse al primer autor a la siguiente dirección: Dirección de Infraestructura y Equipamiento (DGRSS), Secretaría de Salud, Insurgentes Sur 1379, 3er piso, Colonia InsurgentesMixcoac, DF. Código postal 03920, México. Correo electrónico: brust@cenids.ssa.gob.mx
}

necesidad de tecnologías apropiadas para el tratamiento integral del agua es así evidente, tanto más ante la epidemia de cólera que en América Latina ha generado más de un millón de casos $(3,4)$.

La cloración mediante adición de cloro gaseoso o compuestos de cloro, uno de los mejores procedimientos de desinfección del agua $(5,6)$, se ha usado desde comienzos del presente siglo. En época reciente, en los países industrializados donde las condiciones sanitarias son mucho mejores, la cloración ha sido criticada por la posible formación de sustancias carcinó- genas. A pesar de que este procedimiento sigue siendo el más adecuado para destruir microorganismos (7), en México las dificultades técnicas, sociopolíticas, económicas y culturales han hecho que los sistemas de dosificación de soluciones de hipoclorito de sodio sean ineficientes, ya que no se mantienen en funcionamiento regular por la imposibilidad de surtir las soluciones de hipoclorito con la periodicidad y en la cuantía adecuados. Por ello la cloración por el sistema habitual ha resultado inefectiva $\mathrm{y}$, en ocasiones, contraproducente, al generar una falsa idea de potabilidad del agua, en espe- 
cial en comunidades rurales (8) y en las zonas suburbanas que se desarrollan en las periferias metropolitanas sin planes de urbanización y normas reguladoras.

Se planteó así la necesidad de idear procedimientos que permitan a la comunidad obtener gases oxidantes a partir de insumos de uso generalizado, como la sal de cocina, mediante equipos baratos y fáciles de usar que se puedan producir en el país, que impliquen pocos riesgos y que tengan necesidades y costos de mantenimiento mínimos (9). Con el apoyo de la OPS se desarrolló y difundió el sistema MOGGOD (así denominado por su acrónimo en inglés, mixed oxidant gases generated on site device), en el que una celda electrolítica genera una mezcla de gases oxidantes, entre ellos el ozono $\left(\mathrm{O}_{2}\right)$ y el cloro, que se dosifican por medio de un tubo tipo Venturi. Este sistema soluciona la mayor parte de los problemas señalados por Reiff (8).

El núcleo del sistema es la celda de policloruro de vinilo con dos compartimientos separados por una membrana semipermeable, en cada uno de los cuales hay un electrodo: un ánodo de titanio recubierto de iridio-rutenio y un cátodo de acero inoxidable. El compartimiento anódico se llena con una solución acuosa saturada de cloruro de sodio ( $\mathrm{NaCl}$, sal de cocina). En el compartimiento catódico se coloca una solución acuosa de sosa cáustica $(\mathrm{NaOH})$ para iniciar la electrólisis. La energía eléctrica necesaria para la electrólisis ha de ser corriente continua. La dosificación de los gases se realiza por medio de la succión que ocurre en un tubo Venturi al fluir el agua que se ha de desinfectar.

El objetivo del presente estudio fue evaluar, mediante un modelo hidráulico, la eficiencia del sistema MOGGOD y su funcionamiento con energía proporcionada por celdas fotovoltaicas.

\section{MATERIALES Y MÉTODOS}

Para las pruebas de las series 1, 2 y 4 se utilizó un modelo hidráulico en el cual el agua estaba contenida en un tinaco de plástico (Rotoplas ${ }^{\circledR}$ ) de $450 \mathrm{~L}$ (figura 1); para la serie 3 se agregaron tres tinacos plásticos de 1100 L. La tubería de salida, conectada a una válvula (V1), está conectada a una bomba centrífuga (de 0,5 HP de potencia) en la que un rotámetro determina el gasto. A la salida del rotámetro hay una tubería con una válvula (V2) y una derivación con un tubo Venturi. Al abrir más o menos la válvula (V2) se controla el flujo de agua en el tubo Venturi y, por consiguiente, la succión por vacío que se produce. A partir de ahí, la tubería tiene dos válvulas, una (V3) que permite recolectar muestras y otra (V4) que permite el paso del agua a un tanque de filtración con carbón activado, que adsorbe el cloro residual. Desde este tanque el agua regresa al tinaco.

La celda y la fuente de energía eléctrica procedente de un circuito electrónico y transformador conectado a la red se colocaron en una mesa de trabajo cerca del modelo hidráulico. Para preparar la celda, al compartimiento anódico se agregaron $5 \mathrm{~L}$ de agua y $1,5 \mathrm{~kg}$ de $\mathrm{NaCl}$. Este compartimiento se conectó mediante una manguera al tubo Venturi, de tal manera que los gases producidos en el ánodo eran succionados por una presión de unos 15 ó $20 \mathrm{~mm}$ de $\mathrm{Hg}$ (0,29 ó 0,387PSI).
Al compartimiento catódico se agregaron $5 \mathrm{~L}$ de agua y $0,3 \mathrm{~kg}$ de $\mathrm{NaOH}$. Los electrodos se conectaron a la fuente de energía eléctrica y manualmente se ajustó el voltaje de tal forma que la corriente tuviera una intensidad de 10 amperes (A). También se calcularon la corriente consumida por la bomba y la fuente de energía eléctrica, y el consumo total de energía eléctrica utilizada.

Se efectuaron las siguientes series de pruebas:

Serie 1. Serie de ocho pruebas, cada una de 5 horas de duración, en las cuales la celda se preparó después de haberse usado dos veces (10 horas de uso con los mismos insumos).

Serie 2. Serie de 13 pruebas, cada una de 10 horas de duración.

Serie 3. Seis pruebas en que se hizo recircular el agua contenida en cuatro tinacos comunicados entre sí. El volumen total de agua medido con un flujómetro fue de $2,7 \mathrm{~m}^{3}$. Se midió la concentración de cloro en muestras de los cuatro tinacos y se suspendió la prueba al llegar a la concentración máxima medible con el procedimiento utilizado.

Serie 4. Serie de 13 pruebas en que se usaron como fuente de energía eléc-

\section{FIGURA 1. Esquema de un modelo hidráulico para evaluar el funcionamiento del equipo MOGGOD}

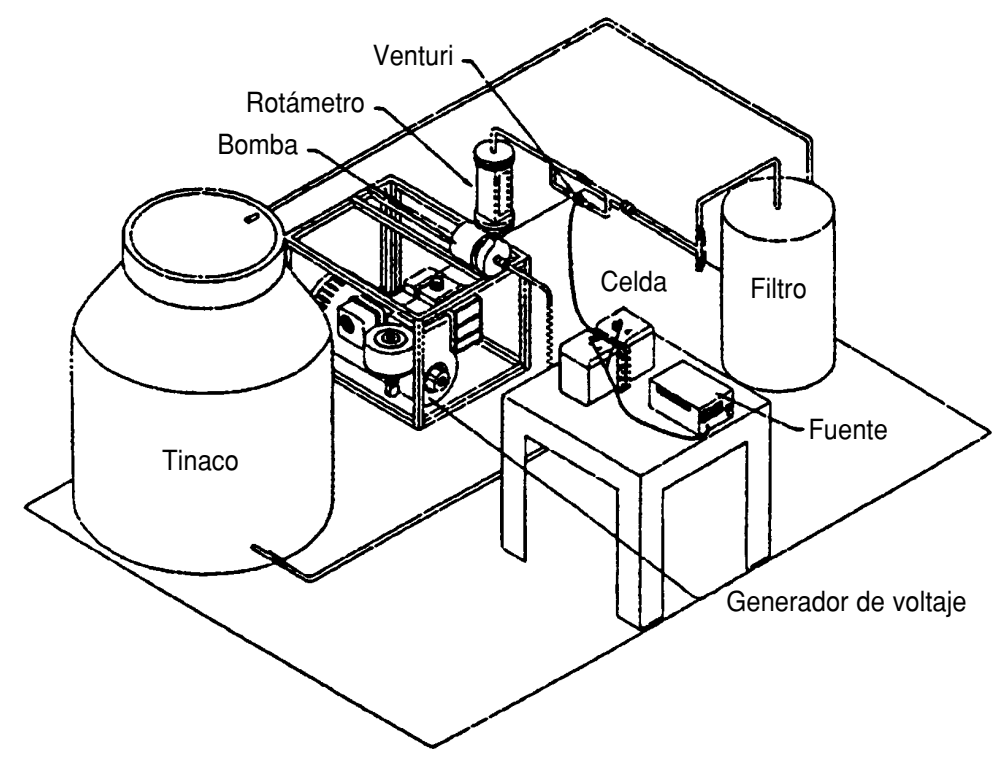


trica dos paneles de 36 células fotovoltaicas cada uno (modelo Pro4JF, 75 W, $600 \mathrm{~V})$, colocados en la azotea de un edificio (a $10 \mathrm{~m}$ sobre el nivel del suelo y a $2240 \mathrm{~m}$ de altura sobre el nivel medio del mar) orientados al sur en el sudeste de la ciudad de México (Tlalpán). El fotovoltaje generado se aplicó directamente a los electrodos de la celda electrolítica, que se preparaba a diario según se describió anteriormente. El bombeo del agua y la dosificación de los gases oxidantes se realizaron recirculando el agua en un tinaco de 450 L. Las pruebas se iniciaron entre las 9.00 y las $10.00 \mathrm{~h}$ en días distribuidos aleatoriamente entre el 8 de agosto y el 8 de septiembre de 1995.

La medición del cloro residual equivalente se realizó de la siguiente manera. Se tomaron muestras de agua, la primera a los 15 minutos de iniciada la prueba y después cada 30 minutos hasta completar el período de observación de 4, 5 y 10 horas según la serie. De cada muestra se tomaron alícuotas de $10 \mathrm{~mL}$, que se agregaron en un tubo de ensayo a $1 \mathrm{~mL}$ de clorhidrato de ortotolidina. Se agitó y al minuto se comparó el color de la solución con los estándares de una regleta en la que había colores correspondientes a concentraciones de 0 a $12 \mathrm{mg} / \mathrm{L}$, a intervalos de $2 \mathrm{mg} / \mathrm{L}$. Cuando la concentración sobrepasó los $12 \mathrm{mg} / \mathrm{L}$ se efectuaron diluciones en las cuales se tomaron $4 \mathrm{~mL}$ y se llevaron a $100 \mathrm{~mL}$ con agua destilada, y de esta solución se tomaron alícuotas de $10 \mathrm{~mL}$ para la reacción (5). Para calcular la cantidad total de cloro residual en el agua tratada, expresada en $\mathrm{mg} / \mathrm{h}$ y en $\mathrm{mg} / \mathrm{L}$, se tuvieron en cuenta la dilución, cuando la hubo, y el flujo de agua en el sistema. Si se multiplica la concentración por el volumen de agua que circula por el sistema en un tiempo dado se obtiene el total de cloro dosificado al agua en ese período.

\section{RESULTADOS}

En las pruebas de la serie 1 (figura 2) el flujo de agua medido con el rotámetro fue de 0,39 L/s. Durante las pruebas se observaba rápidamente
FIGURA 2. Concentraciones de cloro (promedio y promedio más o menos una desviación estándar [DE]) observadas en el agua a distintos intervalos desde el comienzo de las pruebas de 5 horas efectuadas con el sistema MOGGOD

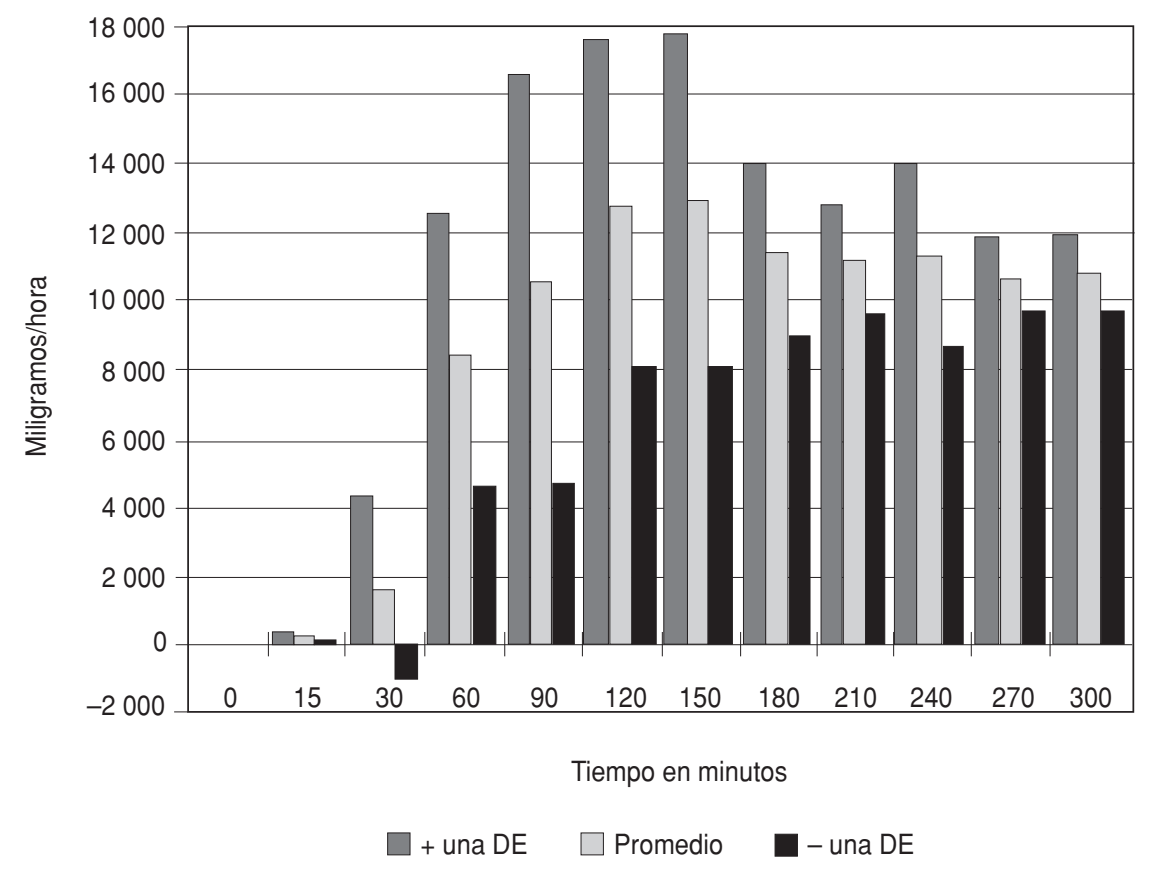

el indicador del rotámetro, que casi no variaba. Al recircular el agua, el cloro residual equivalente fue aumentando progresivamente hasta llegar a $12 \mathrm{mg} / \mathrm{L}$ o más. En tal caso se procedía a efectuar la dilución. La concentración promedio de cloro residual fue de 7,1 mg/L. En los 300 minutos de observación el gasto total de agua fue de $7020 \mathrm{~L}(0,39 \times 60 \times 300)$. El cloro residual total dosificado al agua en ese período de 5 horas puede estimarse en $50 \mathrm{~g}(7,1 \mathrm{mg} / \mathrm{L} \times 7020 \mathrm{~L}=49842 \mathrm{mg})$. Se consumieron $1,5 \mathrm{~kg}$ de $\mathrm{NaCl}$ por cada dos pruebas de 5 horas cada una.

En la serie 2 el flujo promedio en el sistema fue de $0,33 \mathrm{~L} / \mathrm{s}$. El promedio de cloro dosificado al agua en las cuatro pruebas, cada una de 10 horas, fue de unos $82 \mathrm{~g}$ (figura 3).

Esta producción de cloro en ambas series se logró con un consumo de $1,5 \mathrm{~kg}$ de $\mathrm{NaCl}$, a un costo de N\$ 0,80 por $\mathrm{kg} .{ }^{2}$ Los $300 \mathrm{~g}$ de $\mathrm{NaOH}$ necesarios

\footnotetext{
2 Todos los costos se indican en nuevos pesos mexicanos (N\$) que en la época del estudio se cambiaban a razón de 6 pesos por cada dólar estadounidense.
}

para iniciar el funcionamiento del sistema tuvieron un costo de N\$ 4,95 (se usó diariamente $\mathrm{NaOH}$ en reactivo químico, cuyo costo es mayor, para dar mayor constancia a los factores de electrólisis). Al terminar el funcionamiento diario de la celda, la concentración de la $\mathrm{NaOH}$ ha aumentado y la al día siguiente, de forma que el costo es solo del funcionamiento inicial en la comunidad. La potencia eléctrica en watts (W) consumida tanto por la bomba centrífuga como por la fuente de energía se deduce de la intensidad eléctrica en amperes y de la tensión en volts $(\mathrm{V})$, o sea, $8,2 \mathrm{~A} \times 120 \mathrm{~V}=984 \mathrm{~W}$. En 10 horas, el consumo es de $336 \mathrm{~W} \times$ $10 \mathrm{~h}=3360$ watts-hora (Wh ó 3,4 kilowatts-hora, $\mathrm{kWh}$ ), lo que equivale a un costo diario de $\mathrm{N} \$ 8,13$.

El cuadro 1 presenta los datos y costos de los insumos utilizados por el sistema durante un período de 10 horas, que se considera suficiente para tratar unos $200 \mathrm{~m}^{3}$ de agua, ya que las pruebas de campo han indicado que la capacidad oxidante de los gases de la celda es casi el doble, por la actividad solución se puede "guardar" y diluirse 
FIGURA 3. Resultados obtenidos en pruebas de 600 minutos de observación continua con el sistema MOGGOD. Los distintos tipos de columnas representan las concentraciones de cloro en cada una de las cuatro pruebas

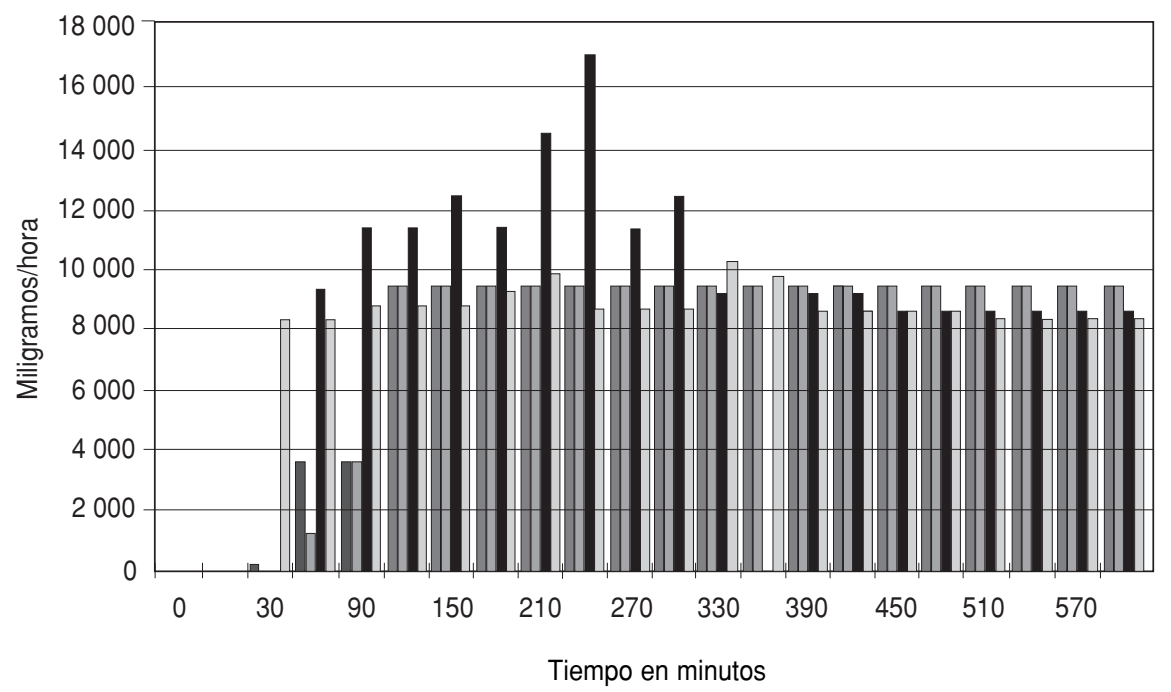

del ozono (8). Eso permite que con poco menos de $100 \mathrm{~g}$ de cloro se puedan tratar unos $200 \mathrm{~m}^{3}$ de agua en 10 horas. El costo total de abastecimiento de agua potabilizada mediante el sistema es de aproximadamente N\$1 000. Si se supone un consumo de 100 L por persona y día, se puede dar servicio a 1848 personas, de forma que el costo por persona y mes es poco más de N\$ 6. Para completar el análisis del costo del sistema debemos agregar

CUADRO 1. Costos de operación de la cloración con el sistema MOGGOD

\begin{tabular}{|c|c|}
\hline Consumo & $\begin{array}{l}\text { Costo } \\
(\mathrm{N} \$)^{\mathrm{a}}\end{array}$ \\
\hline \multicolumn{2}{|l|}{ Diario } \\
\hline Electricidad (10 horas) ${ }^{b}$ & 1,98 \\
\hline Sosa (300 g) & 4,95 \\
\hline Sal de cocina $(1,5 \mathrm{~kg})$ & 1,20 \\
\hline Total & 8,13 \\
\hline \multicolumn{2}{|l|}{ Mensual } \\
\hline Cloro & 243,90 \\
\hline Agua tratada: $5544 \mathrm{~m}^{3, \mathrm{c}}$ & 10977,12 \\
\hline Total & 11221,02 \\
\hline $\begin{array}{l}\text { a Nuevos pesos mexicanos (N\$ } 6 \\
\text { bA razón de } 13,2 \text { kilowatts-ho } \\
\text { por kWh. } \\
\text { cA razón de } 184,8 \mathrm{~m}^{3} / \text { día y de } \mathrm{N} \\
\text { pal de abastecimiento de agua). }\end{array}$ & $\begin{array}{l}\text { de } \mathrm{N} \$ 0,15 \\
\text { rvicio munici- }\end{array}$ \\
\hline
\end{tabular}
empleado (12 mg/L) en los cuatro tinacos a partir de los 170 minutos. Las

el pago de una hora al operador de de bombeo, lo cual significa mínimo es de $\mathrm{N} \$ 32,00$ por 8 horas). Ello equivale a $\mathrm{N} \$ 120,00$ mensuales y a N\$1440,00 anuales (US\$240).

En las pruebas de la serie 3 se recirculó un volumen de 2733 L a razón de 197,6 L/min. Se alcanzó la máxima concentración medible por el método observaciones se suspendieron a los $200 \mathrm{~min}$, lo que representa una dosificación de cloro de $38 \mathrm{~g}$ y un promedio de $11 \mathrm{~g} / \mathrm{h}$ (260 g en 24 horas). Es importante mencionar que dicha concentración de $12 \mathrm{mg} / \mathrm{L}$ se mantuvo durante las 6 horas siguientes del mismo día y que a las 72 horas había disminuido a $10 \mathrm{mg} / \mathrm{L}$.

De acuerdo con el volumen total de agua recirculada se calculó la cantidad de cloro producida en la celda (figura 4). Según la pendiente de la recta de regresión lineal obtenida por el procedimiento de mínimos cuadrados, la producción de cloro es de $185 \mathrm{mg} / \mathrm{min}$.

En las 13 observaciones de la serie 4 en que se utilizó energía solar se obtuvo una tensión promedio de $5,2 \mathrm{~V}$, con un máximo de $7,2 \mathrm{~V}$ y un mínimo de 3,6 V. Este voltaje generó un promedio de 4,2 A con un máximo de 6,3 A y un mínimo de 2,8 A. La producción de cloro dosificado al agua tuvo un promedio de $1369 \mathrm{mg} / \mathrm{L}$ con un máximo de $2506 \mathrm{mg} / \mathrm{L}$ y un mínimo de $17 \mathrm{mg} / \mathrm{L}$, concentración que se observó a los 15 minutos de encendido el sistema (figura 5).

\section{DISCUSIÓN}

La importancia de esta tecnología es evidente, ya que permitiría a las comu-
FIGURA 4. Promedio de cloro dosificado al agua en tres pruebas con el sistema MOGGOD y recta de regresión lineal correspondiente

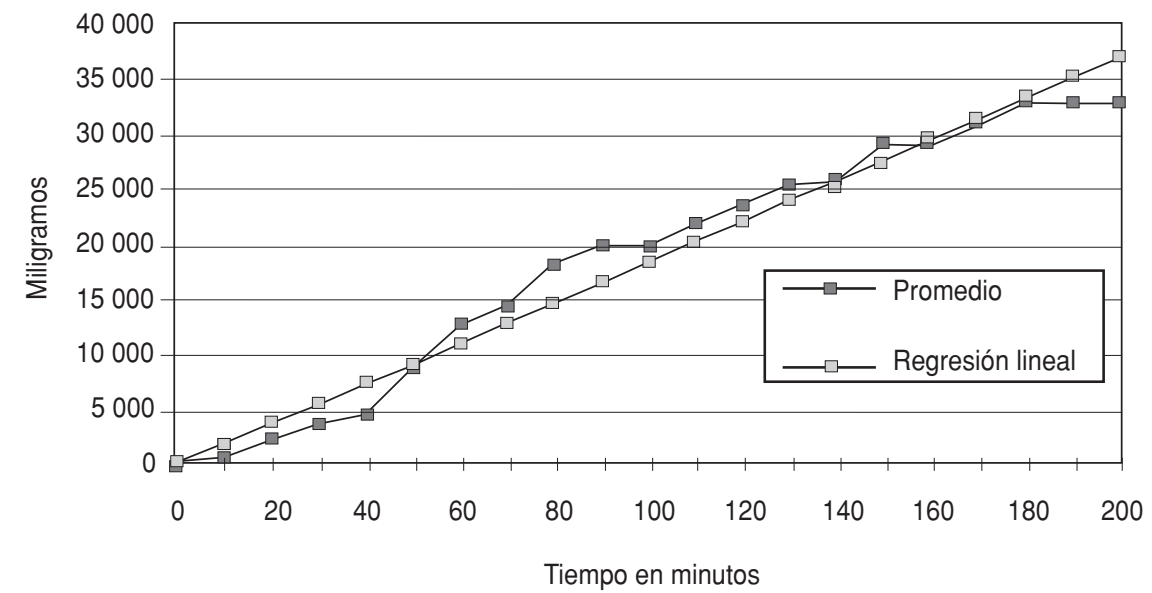

Brust Carmona et al. • Celdas generadoras de gases oxidantes alimentadas con energía eléctrica o solar 
FIGURA 5. Relación entre volts, amperes y la generación de gases oxidantes representada por la cantidad de cloro residual en el agua

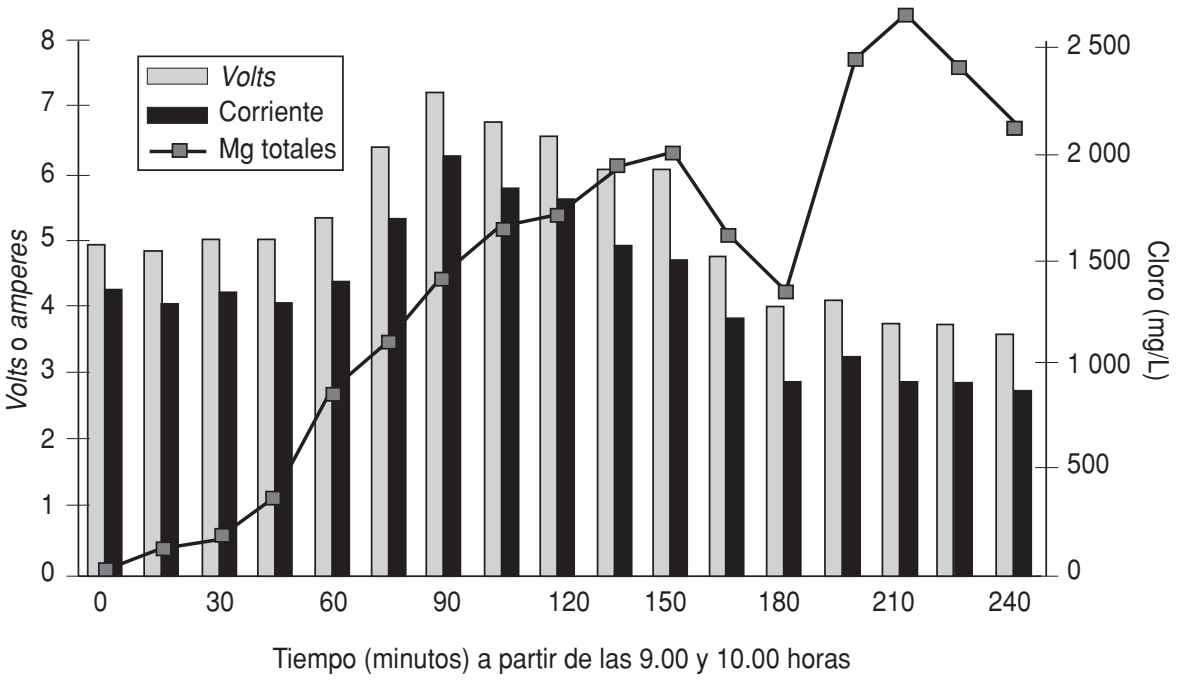

nidades rurales y suburbanas, con el apoyo local del cuidador del equipo de bombeo y del sistema de distribución de agua potable, mantener una buena calidad del agua para uso y consumo humano. Ello redundaría indudablemente en la disminución de algunas de las enfermedades de los pobres, que siguen necesitando el desarrollo o la consolidación de procedimientos o técnicas que solucionen sus problemas (10). De hecho, los problemas que se plantean en la aplicación de esta tecnología están íntimamente relacionados con las necesidades de capacitación del cuidador del sistema y el incremento de responsabilidad.

Como ya se describió en la sección de resultados, el costo de operación de esta tecnología es de solo $\mathrm{N} \$ 8,12$ diarios. Por lo tanto, la producción in situ de las mezclas de gases oxidantes puede proporcionar un desinfectante barato y eficaz para el tratamiento del agua, cuando menos en comunidades latinoamericanas con menos de 2500 habitantes, de las cuales existen en México alrededor de 150000.

Para completar la evaluación de costo-beneficio y comprobar la factibilidad de difundir la aplicación de la tecnología aquí descrita, habría que añadir primero los costos de la compra del equipo (es decir, la inversión ini- cial) y, después, los de las partes y componentes que pueden requerir sustitución al cabo de cierto período. A la inversión en equipo, que es de N\$ 8 700, se suma la instalación, cuyo costo promedio es de $\mathrm{N} \$ 1500$. El total es de N\$ 10200 . Si se calcula que el equipo tiene una vida útil de 6 años - en la Heroica Escuela Naval Militar, en Veracruz, varias celdas han funcionado durante 8 años-, el costo anual es de $\mathrm{N} \$ 1700$. Si hay que cambiar la membrana semipermeable cada año, debe añadirse un costo de $\mathrm{N} \$ 700$. Si se cambia el electrodo de titanio cada 2 total, el costo anual es de N\$ 6167 (cuadro 2). Si se dividen entre las 1848 personas a las que puede abastecer el

CUADRO 2. Costos totales anuales del sistema MOGGOD

\begin{tabular}{ll}
\hline \multicolumn{1}{c}{ Consumo } & $\begin{array}{l}\text { Costo } \\
(\mathrm{N} \$)^{\mathrm{a}}\end{array}$ \\
\hline Anual & \\
Inversión en equipo e instalación & 1700 \\
Repuestos y reparaciones & 1500 \\
Operación & \\
Total & 2967 \\
\hline
\end{tabular}

a Nuevos pesos mexicanos (N\$6 = US\$1).

${ }^{b} A$ razón de $\mathrm{N} \$ 8,13 /$ día. años, el costo es de N\$ 800 anuales. En sistema, cada año se gastan N\$3,34 por persona o $\mathrm{N} \$ 20$ por una familia de seis personas.

Si llegara a quemarse la bomba centrífuga, se gastarían $\mathrm{N} \$ 700$ u 800 adicionales. El recambio del tubo Venturi costaría otros N\$200, y el gasto adicional sería de N\$ 1000 en total. Esta suma dividida entre el número de usuarios daría un incremento anual de $\mathrm{N} \$ 0,54$, gasto que sigue siendo sustentable por la comunidad.

Otra comparación importante es con el costo de la desinfección del agua mediante la adición de hipoclorito de sodio en solución al 10\% (en $\mathrm{g} / 100 \mathrm{~mL}$ ). Esa concentración se propone como promedio, ya que al salir de la fábrica se dice que la solución tiene una concentración de $13 \%$, pero esta disminuye por muchos factores durante el transporte, los cambios de envase, el tiempo transcurrido hasta su utilización, etc. Según un estudio estadounidense, una solución al 16,7\% almacenada a $27^{\circ} \mathrm{C}$ pierde $10 \%$ de su concentración en 10 días y $20 \%$ en 25 días, dentro de tanques especiales anticorrosivos y no traslúcidos (11), que no suelen existir en México. Para obtener los 200 g que genera la celda electrolítica se necesitan $2 \mathrm{~L}$ de solución al $10 \%$ a un costo diario de $\mathrm{N} \$ 5,60$ (N\$ 168,00 al mes y de $\mathrm{N} \$ 2016,00 \mathrm{al}$ año), en lugar de $\mathrm{N} \$ 1,20$ al día, que es el costo de la sal de cocina ( $\mathrm{N} \$ 36,00 \mathrm{al}$ mes y N\$432,00 al año).

En México la poca fiabilidad en cuanto a la potabilidad del agua que suministra la red pública ha hecho que se extienda la venta de garrafones (bidones) de $20 \mathrm{~L}$ a un precio de $\mathrm{N} \$ 5$ a 8 por garrafón. Una familia de seis miembros consume para beber y cocinar un promedio de cinco garrafones a la semana $(100 \mathrm{~L} \div 7$ días $=14,2 \mathrm{~L} /$ día; $14,2 \mathrm{~L} /$ día $\div 6$ personas $=2,3 \mathrm{~L} /$ día $/$ persona), a un costo semanal de $\mathrm{N} \$ 25$ a $\mathrm{N} \$ 40$. Esta cifra naturalmente no cubre el costo del agua necesaria para lavar los utensilios de cocina y comedor, así como las frutas y verduras (indispensable en México), cepillarse los dientes, lavar la ropa, bañarse, y demás. Usar agua de garrafón para estos fines sería absurdo y significaría un gasto mensual de $\mathrm{N} \$ 4500$ a 
N\$ 7 000. En cambio, con los N\$36,00 mensuales que cuesta el sistema MOGGOD la misma familia podría adquirir el suministro mínimo de agua recomendado por la OPS.

La tecnología MOGGOD es apropiada para las comunidades rurales y suburbanas económicamente deprimidas. Incluso podría usarse en ciudades pequeñas si se dispusiera de series de celdas, con lo que se evitaría la mayor concentración de cloro para los primeros usuarios del sistema de distribución de agua, se ahorraría dinero en la compra de hipoclorito y se reducirían la carga administrativa y los riesgos mencionados en la introducción de este trabajo. Con un costo algo mayor por los paneles de celdas fotovoltaicas (N\$ 3 044), la tecnología MOGGOD se puede utilizar también en comunidades que no tienen electricidad pero que sí disponen de un sistema de distribución de agua por gravedad. En un simposio internacional sobre tecnologías para la producción de desinfectantes a nivel local, celebrado en Santiago de Cuba del 4 a 6 de junio de 1995 y patrocinado por la OPS/OMS, se comunicaron resultados alentadores que fueron obtenidos mediante sistemas de este tipo.

\section{REFERENCIAS}

1. Kumate J, Isibasi A, Llausas A. Perspectivas en la investigación de las enfermedades infecciosas y parasitarias. En: Velázquez Arellano A, comp. La salud en México y la investigación clínica. México, DF: UNAM; 1985:9-21.

2. Consejo Nacional para el Control de las Enfermedades Diarreicas. Informe de actividades 1993-1994. Salud Publica Mex 1994;36:552-561.

3. Holden C. Purification of water in the time of cholera. Science 1994;265:476.

4. Últimas noticias sobre el cólera en las Américas. El Hospital (Cincinnati, Ohio) 1995;(feb.mar.):96.

5. Organización Panamericana de la Salud. Volumen 3: Control de la calidad del agua potable en sistemas de abastecimiento para pe- queñas comunidades. En: Guías para la calidad del agua potable. Washington, DC: OPS; 1988: 127-131.

6. Lippy EC. Chlorination to prevent and control waterborne diseases. Journal AWWA (American Water Works Association) 1986;49:52.

7. Amato I. The crusade against chlorine. Science 1993;261:152-154.

8. Reiff F. M. Desinfección del agua con una mezcla de gases oxidantes producidos in situ (MOGGOD). Bol Oficina Sanit Panam 1988; 105:371-389.

9. Martínez Ramírez G. Uso de una mezcla de gases oxidantes generados "in situ" en la desinfección del agua. Bol Invest Desarrollo Tecnol Salud (México, SSA)1988;2:6-18.
10. Grant JP. Cómo usar el conocimiento biomédico en el Tercer Mundo. En: Bloom BR, Cerami A, comps. Investigación biomédica para el desarrollo. México, DF: Fondo de Cultura Económica; 1994.

11. Tchobanoglous G, Burton FL, eds. Metcalf and Eddy Inc.-Wastewater engineering: treatment, disposal, and reuse. 3a ed. New York: McGraw Hill; 1991.

Manuscrito recibido el 15 de marzo de 1996 y aceptado para publicación en versión revisada el 14 de noviembre de 1996.

ABSTRACT Diseases caused by microbial contaminants in drinking water continue to be a serious problem in countries like Mexico. Chlorination, using chlorine gas or chlorine compounds, is one of the best ways to treat drinking water. However, difficulties in handling chlorine gas and the inefficiency of hypochlorite solution dosing systems-due to sociopolitical, economic, and cultural factors-have reduced the utility of these chlorination procedures, especially in far-flung and inaccessible rural communities. These problems led to the development of appropriate technologies for the disinfection of water by means of the on-site generation of mixed oxidant gases (chlorine and ozone). This system, called MOGGOD, operates through the electrolysis of a common salt solution. Simulated system evaluation using a hydraulic model allowed partial and total costs to be calculated. When powered by electrical energy from the community power grid, the system had an efficiency of $90 \%$, and in 10 hours it was able to generate enough gases to disinfect about $200 \mathrm{~m}^{3}$ of water at a cost of approximately N\$ 8 (US\$ 1.30). When the electrolytic cell was run on energy supplied through a photoelectric cell, the investment costs were higher. A system fed by photovoltaic cells could be justified in isolated communities that lack electricity but have a gravityfed water distribution system. 